\title{
Supporting Information \\ Quantity or Quality: Are Self-Healing Polymers and Elastomers Always Tougher with more Hydrogen Bonds?
}

Sean C. Cummings, ${ }^{a}$ Obed J. Dodo, ${ }^{a}$ Alexander C. Hull, ${ }^{a}$ Borui Zhang, ${ }^{a, \dagger}$ Camryn P. Myers, ${ }^{a}$ Jessica L. Sparks, ${ }^{b}$ Dominik Konkolewicz ${ }^{*, a}$

a Department of Chemistry and Biochemistry, Miami University, 651 E High St. Oxford, OH, 45056, USA

b Department of Chemical Paper and Biomedical Engineering, Miami University, 650 E High St. Oxford, OH, 45056, USA

* Corresponding author: d.konkolewicz@miamiOH.edu

\section{Experimental}

\section{Materials}

All materials were obtained from commercial suppliers and used as received unless otherwise stated.

Synthesis of 2-(propionic acid)yldodecyl trithiocarbonate (PADTC)

PADTC was synthesized as outlined in the literature. ${ }^{1}$ 


\section{Synthesis of 2-(((6-(3-(6-methyl-4-oxo-1,4-dihydropyrimidin-2- yl)ureido)hexyl)carbamoyl)oxy)ethyl acrylate (UPyA)}

UPyA was synthesized as outlined in the literature. ${ }^{2}$

\section{Synthesis of furfuryl methacrylate (FMA)}

FMA was synthesized as outlined in the literature. ${ }^{3}$

\section{Synthesis of a typical RAFT UPy HEA polymer (Poly(HEA 100-UPyA 7.5))}

To a $50 \mathrm{~mL}$ round bottom flask containing a magnetic stirrer bar, UPyA powder (1.3268 g, $0.0032 \mathrm{~mol}$ ) and $9.9855 \mathrm{~g}$ dimethylformamide (DMF) were added. The reaction mixture was capped with a rubber septum, and then allowed to homogenize for 5 minutes at $65^{\circ} \mathrm{C}$, followed by deoxygenating with nitrogen for $20 \mathrm{~min}$ at ambient temperature. Meanwhile, PADTC (0.3019 $\mathrm{g}, 0.0009 \mathrm{~mol}$ ), azobisisobutyronitrile (AIBN, $0.0282 \mathrm{~g}, 0.0002 \mathrm{~mol})$, hydroxyethyl acrylate (HEA, $5.0000 \mathrm{~g}, 0.0431 \mathrm{~mol}$ ) were added in a small vial and the prepared reaction mixture was transferred to the round bottom flask via syringe, while the whole system was still being purged with nitrogen. After deoxygenation, the reaction was stirred at $65^{\circ} \mathrm{C}$ overnight. The resulting Poly(HEA ${ }_{100-U P y A}$ 7.5) polymer solution was confirmed by $500 \mathrm{MHz}$ 1H-NMR with above 95\% conversion. The materials were analyzed by size exclusion chromatography (SEC) to evaluate molecular weight distribution.

\section{Synthesis of a typical RAFT UPy EA polymer (Poly(EA100-UPyA 7.5))}

To a $50 \mathrm{~mL}$ round bottom flask containing a magnetic stirrer bar, UPyA powder (1.5389 g, $0.0037 \mathrm{~mol}$ ) and $10.0956 \mathrm{~g}$ dimethylformamide (DMF) were added. The reaction mixture was 
capped with a rubber septum, and then allowed to homogenize for 5 minutes at $65^{\circ} \mathrm{C}$, followed by deoxygenating with nitrogen for $20 \mathrm{~min}$ at ambient temperature. Meanwhile, PADTC (0.1751 $\mathrm{g}, 0.0005 \mathrm{~mol}$ ), azobisisobutyronitrile (AIBN, $0.0164 \mathrm{~g}, 0.0001 \mathrm{~mol})$, ethyl acrylate (EA, 5.0000 $\mathrm{g}, 0.0499 \mathrm{~mol}$ ) were added in a small vial and the prepared reaction mixture was transferred to the round bottom flask via syringe, while the whole system was still being purged with nitrogen. After deoxygenation, the reaction was stirred at $65^{\circ} \mathrm{C}$ overnight. The resulting Poly(EA100UPyA 7.5) polymer solution was confirmed by $500 \mathrm{MHz} 1 \mathrm{H}-\mathrm{NMR}$ with above $95 \%$ conversion. The materials were analyzed by size exclusion chromatography (SEC) to evaluate molecular weight distribution.

\section{Synthesis of a typical RAFT FMA HEA polymer (Poly(HEA 100-FMA $\left.{ }_{7.5}\right)$ )}

To a $50 \mathrm{~mL}$ round bottom flask equipped with a magnetic stirrer bar, PADTC $(0.1510 \mathrm{~g}, 0.0004$ mol), AIBN (0.0141 g, $0.0001 \mathrm{~mol})$, HEA (5.0000 g, $0.0431 \mathrm{~mol})$, FMA (0.5367 g, $0.0032 \mathrm{~mol})$ and $8.5526 \mathrm{~g}$ dimethylformamide (DMF) were added. The reaction mixture was capped with a rubber septum and purged with nitrogen for $20 \mathrm{~min}$. The reaction was stirred at $65^{\circ} \mathrm{C}$ for $2 \mathrm{~h}$. The resulting Poly(HEA100-FMA7.5) polymer solution was confirmed by $500 \mathrm{MHz}$ 1H-NMR with above $80 \%$ conversion. The crude product was precipitated by dropwise addition to stirred diethyl ether. The product was dried overnight in a vacuum oven giving Poly(HEA $\left.100-\mathrm{FMA}_{7.5}\right)$. The materials were analyzed by SEC to evaluate molecular weight distribution.

\section{Synthesis of a typical RAFT FMA EA polymer (Poly(EA100-FMA 7.5))}

To a $50 \mathrm{~mL}$ round bottom flask equipped with a magnetic stirrer bar, PADTC $(0.1751 \mathrm{~g}, 0.0005$ mol), AIBN (0.0164 g, $0.0001 \mathrm{~mol})$, EA (5.0000 g, 0.0499 mol), FMA (0.6224 g, 0.0037 mol) 
and $8.7208 \mathrm{~g}$ dimethylformamide (DMF) were added. The reaction mixture was capped with a rubber septum and purged with nitrogen for $20 \mathrm{~min}$. The reaction was stirred at $65^{\circ} \mathrm{C}$ for $5 \mathrm{~h}$. The resulting Poly(EA 100-FMA7.5) polymer solution was confirmed by $500 \mathrm{MHz}$ 1H-NMR with above $80 \%$ conversion. The crude product was precipitated by dropwise addition to stirred hexanes. The product was dried overnight in a vacuum oven giving Poly(EA100-FMA7.5). The materials were analyzed by SEC to evaluate molecular weight distribution.

\section{Synthesis of a typical RAFT EA polymer $(\operatorname{Poly}(\mathbf{E A 1 0 0}))$}

To a $50 \mathrm{~mL}$ round bottom flask equipped with a magnetic stirrer bar, PADTC $(0.1751 \mathrm{~g}, 0.0005$ $\mathrm{mol}), \operatorname{AIBN}(0.0164 \mathrm{~g}, 0.0001 \mathrm{~mol}), \mathrm{EA}(5.0000 \mathrm{~g}, 0.0499 \mathrm{~mol})$, and $7.7872 \mathrm{~g}$ dimethylformamide (DMF) were added. The reaction mixture was capped with a rubber septum and purged with nitrogen for $20 \mathrm{~min}$. The reaction was stirred at $65{ }^{\circ} \mathrm{C}$ for $8 \mathrm{~h}$. The resulting Poly(EA100) polymer solution was confirmed by $500 \mathrm{MHz} 1 \mathrm{H}-\mathrm{NMR}$ with above $95 \%$ conversion. The crude product was precipitated by dropwise addition to stirred 50:50 mixture of ethanol and water. The product was dried overnight in a vacuum oven giving Poly(EA100). The materials were analyzed by SEC to evaluate molecular weight distribution.

\section{Synthesis of a typical RAFT HEA polymer (Poly(HEA100))}

To a $50 \mathrm{~mL}$ round bottom flask equipped with a magnetic stirrer bar, PADTC $(0.1509 \mathrm{~g}, 0.0004$ mol), AIBN (0.0141 g, $0.0001 \mathrm{~mol})$, HEA (5.0000 g, $0.0431 \mathrm{~mol})$, and $7.7903 \mathrm{~g}$ dimethylformamide (DMF) were added. The reaction mixture was capped with a rubber septum and purged with nitrogen for $20 \mathrm{~min}$. The reaction was stirred at $65{ }^{\circ} \mathrm{C}$ for $8 \mathrm{~h}$. The resulting Poly(HEA 100) polymer solution was confirmed by $500 \mathrm{MHz} 1 \mathrm{H}-\mathrm{NMR}$ with above $95 \%$ 
conversion. The crude product was precipitated by dropwise addition to stirred Toluene. The product was dried overnight in a vacuum oven giving Poly(HEA 100). The materials were analyzed by SEC to evaluate molecular weight distribution.

\section{Typical Interpenetrated Network Polymer Synthesis}

Poly(EA 100-FMA7.5-UPyA 7.5) is used here as an example to demonstrate the general procedure of making interpenetrated networks. The prepared dry Poly(EA $100-$ FMA $\left._{7.5}\right)$ polymer was weighed and the realized mass $(4.8734 \mathrm{~g}, 0.0004 \mathrm{~mol})$ was taken to calculate the theoretical weight of Poly(EA 100-UPyA 7.5) polymer-DMF solution, in order to combine two polymers as $1: 1$ ratio with respect to polymer weight (mass basis). In this case, 12.1835 g Poly(EA 100-UPy $\left.A_{7.5}\right)$ polymer-DMF solution was added to the Erlenmeyer flask containing precipitated Poly(EA $100^{-}$ FMA7.5) polymer and homogenized via sonicator. In a separate vial, 1,1' (methylenedi-4,1 phenylene)bismaleimide (BMI) (0.6072 g, $0.0014 \mathrm{~mol})$ was dissolved in $2.4367 \mathrm{~g}$ of DMF and, then transferred into the flask containing the prepared polymer mixture solution. Once fully dissolved and homogenized, the contents of the flask were transferred to a Teflon mold to process polymerization at $45-50{ }^{\circ} \mathrm{C}$ for $48 \mathrm{~h}$. After crosslinking, the materials were removed from the Teflon mold and allowed to dry in the fume hood for $24 \mathrm{~h}$ and overnight in a thermal oven.

\section{Nuclear Magnetic Resonance (NMR)}

All NMR experiments were performed on a Bruker Advance 300 or $500 \mathrm{MHz}$ spectrometer. 


\section{Determination of number average molecular weight (Mn) and composition by NMR}

Typical PHEA-FMA materials, 0.88 ppm (PADTC-CH3) was calibrated to 3H, 4.1 ppm (HEA$\mathrm{CH}_{2}$ at ester) was integrated and divided by 2 (2H from HEA) delivering the HEA units. Then, 6.49 ppm (FMA-aromatic) was integrated and divided by 2 (2H from FMA) delivering FMA units.

Typical PHEA-UPyA materials, 0.88 ppm (PADTC-CH3) was calibrated to $3 \mathrm{H}, 3.58$ ppm (HEA$\mathrm{CH}_{2}$ adjacent to $\mathrm{OH}$ group) was integrated and divided by 2 ( $2 \mathrm{H}$ from $\left.\mathrm{HEA}\right)$ delivering the HEA units. The $3.58 \mathrm{ppm}$ (HEA) integral value was subtracted from $4.1 \mathrm{ppm}$ (HEA+UPyA) integral value, the result was divided by $4\left(4 \mathrm{H}\right.$ from UPyA from $\mathrm{CH}_{2}$ at UPyA ester and $\mathrm{CH}_{2}$ at UPyA NHCOO $\underline{\mathrm{CH}} 2$ urethane) delivering the UPyA units.

Typical PEA-FMA materials, 3.36 ppm (PADTC- $\mathrm{CH}_{2}$ at trithiocarbonate) was calibrated to $2 \mathrm{H}$, $4.1 \mathrm{ppm}\left(\mathrm{EA}-\mathrm{CH}_{2}\right.$ at ester) was integrated and divided by 2 ( $2 \mathrm{H}$ from EA) delivering EA units. Peak at $6.41 \mathrm{ppm}$ (FMA-aromatic) was integrated and divided by 2 (2H from FMA) delivering the FMA units.

Typical PEA-UPyA materials, 0.88 ppm (PADTC- $\left.\mathrm{CH}_{3}\right)$ was calibrated to $3 \mathrm{H}$, the peaks near 3.20 ppm (UPyA) were integrated and divided by 4 ( $2 \mathrm{H}$ from UPyA urethane protons $\underline{\mathrm{CH}_{2}} \mathrm{NHCOOCH}_{2}$

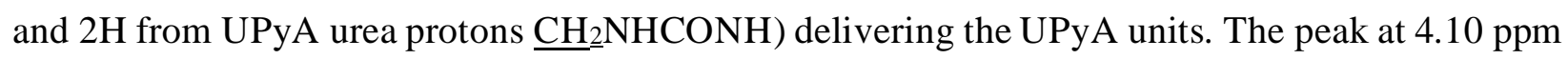
was integrated, and the resulting integral at $4.1 \mathrm{ppm}$ had the integral values of the peaks near 3.2 ppm subtracted $\left(4 \mathrm{H}\right.$ from UPyA from $\mathrm{CH}_{2}$ at UPyA ester and $\mathrm{CH}_{2}$ at $\mathrm{UPyA} \mathrm{NHCOOCH}_{2}$ urethane), and the remaining signal, divided by 2 ( $2 \mathrm{H}$ from $\mathrm{EA} \mathrm{CH}_{2}$ ester protons) delivering the EA units. 
$\mathrm{M}_{\mathrm{n}}$ by NMR is typically calculated via multiplying monomer units by their respective molecular weights, a sum of the resulting values and the molecular weight of the chain transfer agent (PADTC) gives the experimental $\mathrm{M}_{\mathrm{n}}$ value (See Table $\mathrm{S} 1$ and $\mathrm{S} 2$ ).

\section{Infrared (IR) spectroscopy}

All IR spectra were collected using a Bruker IFS 66/S Fourier transform spectrometer equipped with a tungsten halogen lamp, a CaF2 beam splitter, and a liquid nitrogen cooled InSb detector.

\section{Differential Scanning Calorimetry (DSC)}

All DSC experiments were performed on a TA instruments Q20 or Q2000 DSC system using a heating, cooling, heating cycle. For polymer networks, heat flow was monitored between -40 and $150{ }^{\circ} \mathrm{C}$ with a heating rate of $10^{\circ} \mathrm{C} / \mathrm{min}$ and a cooling rate of $5^{\circ} \mathrm{C} / \mathrm{min}$. For homopolymers, heat flow was monitored between -60 and $150{ }^{\circ} \mathrm{C}$ with a heating rate of $10{ }^{\circ} \mathrm{C} / \mathrm{min}$ and a cooling rate of $5{ }^{\circ} \mathrm{C} / \mathrm{min}$. Only data from the second heating cycle was analyzed.

\section{Size Exclusion Chromatography (SEC)}

SEC was used to determine polymer molecular weight and dispersity data using an Agilent 1260 SEC system equipped with an autosampler, an Agilent 1260 isocratic pump, Agilent 1 guard and 2 analytical Polar Gel-M columns, degasser, and Agilent 1260 refractive index (RI detector). $N, N$ Dimethylformamide $(\mathrm{DMF})+0.1 \mathrm{wt} \% \mathrm{LiBr}$ at $50{ }^{\circ} \mathrm{C}$ was the eluent at a flow rate of $1 \mathrm{~mL} / \mathrm{min}$. Each sample was filtered before injection. The SEC system was calibrated with poly(methyl methacrylate) standards, with conventional calibration for the determination of molecular weights and dispersities. 


\section{Tensile methods}

An Instron 3344 universal testing system equipped with a $100 \mathrm{~N}$ load cell was used at room temperature for all tensile tests. The elongation of the materials was increased at rate of $0.05 \mathrm{~mm}$ $\mathrm{s}^{-1}$. The fracture toughness and self-healing experiments were performed until failure for notched samples all self-healed samples respectively.

\section{Young's Modulus Calculations}

The Ogden hyperelastic model was used to determine the Young's modulus (E). The engineering stress $(\sigma)$ was fitted with the following equation ${ }^{4}$ :

$$
=\frac{2 G}{1} \quad 1(/ 2) \quad \text { Eq. S1 }
$$

where, $G$ is the shear modulus, $\alpha$ is the strain hardening exponent, and $\lambda$ is the stretch ratio given by $\lambda=\varepsilon+1$, where $\varepsilon$ is the applied strain. $G$ and $\alpha$ were found for each sample by fitting Eq. S1 to the experimental stress-strain data, and the elastic modulus $(E)$ was found from Eq. S2:

$$
E=2 G(1+v) \quad \text { Eq. S2 }
$$

where $v$ is Poisson's ratio (taken as 0.5 for an incompressible material). The mean and standard error were determined by fitting 3 replicates.

\section{Fracture energy determination}

An Instron 3344 universal testing system equipped with a $100 \mathrm{~N}$ load cell was used at room temperature for all fracture test. Samples were divided into two groups designate "notched" and 
"unnotched". Materials of the cut group were notched half way through their respective width before being loaded onto the Instron in a manner that maintains the notch on a horizontal plane. The samples were then subjected to tensile tests. Unnotched materials were left without a notch and subject to the same tensile tests. Fracture energy was determined by integrating the stressstrain curve of the uncut samples up to the mean strain at break for the cut samples.

\section{Self-Healing Procedures}

Materials subjected to self-healing was first sliced in half with a razor blade and the two separate ends of such material was then pressed backed together at the sliced area using mild pressure from fingers. Afterwards all of the materials, both cut and uncut were placed into an oven at $90{ }^{\circ} \mathrm{C}$ for 24 hours to expose the materials to equivalent thermal conditions. Samples were then subjected to tensile tests. For cold self-healing performed under ambient conditions, the similar steps were followed except, the materials were not heated. 


\section{Additional experimental data}

Table S1. Molecular weight data for RAFT PEA polymers synthesized. $\mathrm{M}_{\mathrm{n}-\mathrm{NMR}}$ is calculated as $\mathrm{M}_{\text {Cta }}+$ Unitsea $\times \mathrm{M}_{\mathrm{EA}}+$ Unitsupya $\times \mathrm{MUPyA}_{\mathrm{U}}+$ Unitsfma $\times \mathrm{M}_{\mathrm{Fma}} . \mathrm{M}_{\mathrm{n} \text {-th }}$ is calculated as

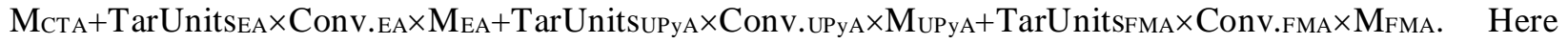
TarUnits is the targeted number of units and Units is the number of units measured by NMR, and Conv. refers to monomer conversion. Total H-bond donor is the calculated total number of hydrogen bond donors given by CTA $+4 \times$ UnitsuPyA, since each CTA has 1 hydrogen bond donor on the initiating group and each UPyA unit has 4 hydrgogen bond donors.

\begin{tabular}{|c|c|c|c|c|c|c|c|c|c|c|}
\hline Polymer & $\begin{array}{c}\text { Conv. } \\
\text { EA }\end{array}$ & $\begin{array}{c}\text { Units } \\
\text { EA }\end{array}$ & $\begin{array}{c}\text { Conv. } \\
\text { UPyA } \\
\text { or } \\
\text { FMA }\end{array}$ & $\begin{array}{l}\text { Units } \\
\text { UPyA }\end{array}$ & $\begin{array}{l}\text { Units } \\
\text { FMA }\end{array}$ & $\begin{array}{c}\text { Total } \\
\text { H- } \\
\text { bond } \\
\text { donor }\end{array}$ & $\mathrm{Mn}_{\mathrm{n}} \mathrm{Th}$ & $\mathrm{Mn}_{\mathrm{n}-\mathrm{NMR}}$ & $\mathrm{Mn}_{\mathrm{n}-\mathrm{SEC}}$ & $\mathrm{M}_{\mathrm{w}} / \mathrm{M}_{\mathrm{n}-\mathrm{SEC}}$ \\
\hline $\mathrm{PEA}_{100-\mathrm{FMA}}$ & 88 & 98 & $>95$ & 0 & 5 & 1 & 10000 & 11000 & 12000 & 1.44 \\
\hline $\mathrm{PEA}_{100}-\mathrm{UPyA}_{5}$ & $>95$ & 92 & $>95$ & 5 & 0 & 21 & 12000 & 12000 & 16000 & 1.20 \\
\hline $\mathrm{PEA}_{100-\mathrm{FMA}} 7.5$ & 86 & 99 & $>95$ & 0 & 8 & 1 & 10000 & 12000 & 12000 & 1.48 \\
\hline PEA100-UPyA7.5 & $>95$ & 90 & $>95$ & 7 & 0 & 29 & 13000 & 12000 & 17000 & 1.23 \\
\hline PEA $50-F M A 3.75$ & 90 & 63 & $>95$ & 0 & 4 & 1 & 5500 & 7300 & 6300 & 1.34 \\
\hline PEA50-UPyA 3.75 & $>95$ & 41 & $>95$ & 3 & 0 & 13 & 6600 & 5700 & 9000 & 1.21 \\
\hline PEA50 & $>95$ & 57 & - & 0 & 0 & 1 & 5300 & 6100 & 5500 & 1.20 \\
\hline $\mathrm{PEA}_{100}$ & $>95$ & 119 & - & 0 & 0 & 1 & 10000 & 12000 & 11000 & 1.18 \\
\hline
\end{tabular}

Table S2. Molecular weight data for RAFT PHEA polymers synthesized. $\mathrm{M}_{\mathrm{n}-\mathrm{N} M R}$ is calculated as

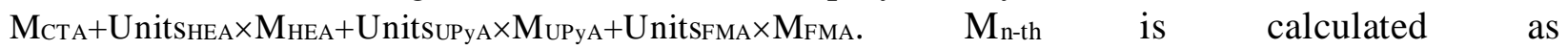

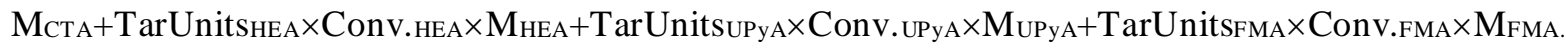
Here TarUnits is the targeted number of units and Units is the number of units measured by NMR, and Conv. refers to monomer conversion. Total H-bond donor is the calculated total number of hydrogen bond donors given by CTA $+4 \times$ UnitsuPyA + UnitshEA, since each CTA has 1 hydrogen bond donor on the initiating group, each HEA unit has 1 hydrogen bond donor, and each UPyA unit has 4 hydrgogen bond donors.

\begin{tabular}{|c|c|c|c|c|c|c|c|c|c|c|}
\hline Polymer & $\begin{array}{l}\text { Conv. } \\
\text { HEA }\end{array}$ & $\begin{array}{l}\text { Units } \\
\text { HEA }\end{array}$ & $\begin{array}{c}\text { Conv } \\
\text { UPyA } \\
\text { or } \\
\text { FMA }\end{array}$ & $\begin{array}{l}\text { Units } \\
\text { UPyA }\end{array}$ & $\begin{array}{l}\text { Units } \\
\text { FMA }\end{array}$ & $\begin{array}{c}\text { Total } \\
\text { H- } \\
\text { bond } \\
\text { donor } \\
\end{array}$ & $\mathrm{M}_{\mathrm{n}-\mathrm{Th}}$ & $\mathrm{M}_{\mathrm{n}-\mathrm{NMR}}$ & $\mathrm{M}_{\mathrm{n}-\mathrm{SEC}}$ & $\mathrm{M}_{\mathrm{w}} / \mathrm{M}_{\mathrm{n}-\mathrm{SEC}}$ \\
\hline PHEA $_{100}-\mathrm{FMA}_{5}$ & 79 & 92 & $>95$ & 0 & 5 & 93 & 10000 & 12000 & 18000 & 1.29 \\
\hline PHEA $_{100-U P y A}$ & $>95$ & 112 & $>95$ & 5 & 0 & 123 & 14000 & 15000 & 22000 & 1.23 \\
\hline PHEA $_{100}-$ FMA $_{7.5}$ & 74 & 79 & $>95$ & 0 & 7 & 80 & 10000 & 11000 & 16000 & 1.33 \\
\hline PHEA $_{100-U_{P y}} 7.5$ & $>95$ & 102 & $>95$ & 7 & 0 & 131 & 15000 & 15000 & 25000 & 1.17 \\
\hline PHEA50-FMA 3.75 & 73 & 41 & $>95$ & 0 & 4 & 42 & 5300 & 5800 & 7700 & 1.22 \\
\hline PHEA $_{50-U P y} A_{3.75}$ & $>95$ & 56 & $>95$ & 4 & 0 & 77 & 7700 & 8500 & 12000 & 1.19 \\
\hline PHEA$_{50}$ & $>95$ & 55 & - & 0 & 0 & 56 & 6000 & 6700 & 9600 & 1.25 \\
\hline PHEA 100 & $>95$ & 110 & - & 0 & 0 & 111 & 12000 & 13000 & 17000 & 1.25 \\
\hline
\end{tabular}




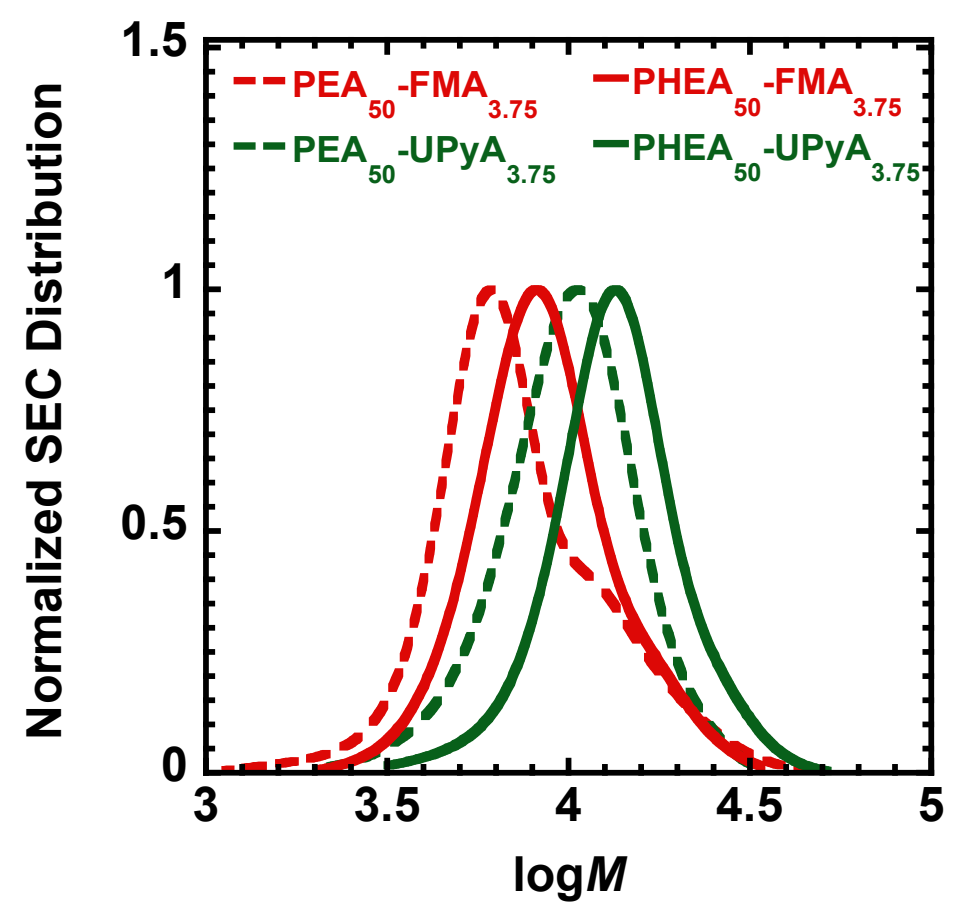

Figure S1. SEC traces of PEA50-FMA3.75, PEA50-UPyA3.75, PHEA50-FMA3.75, and PHEA50UPyA3.75. 

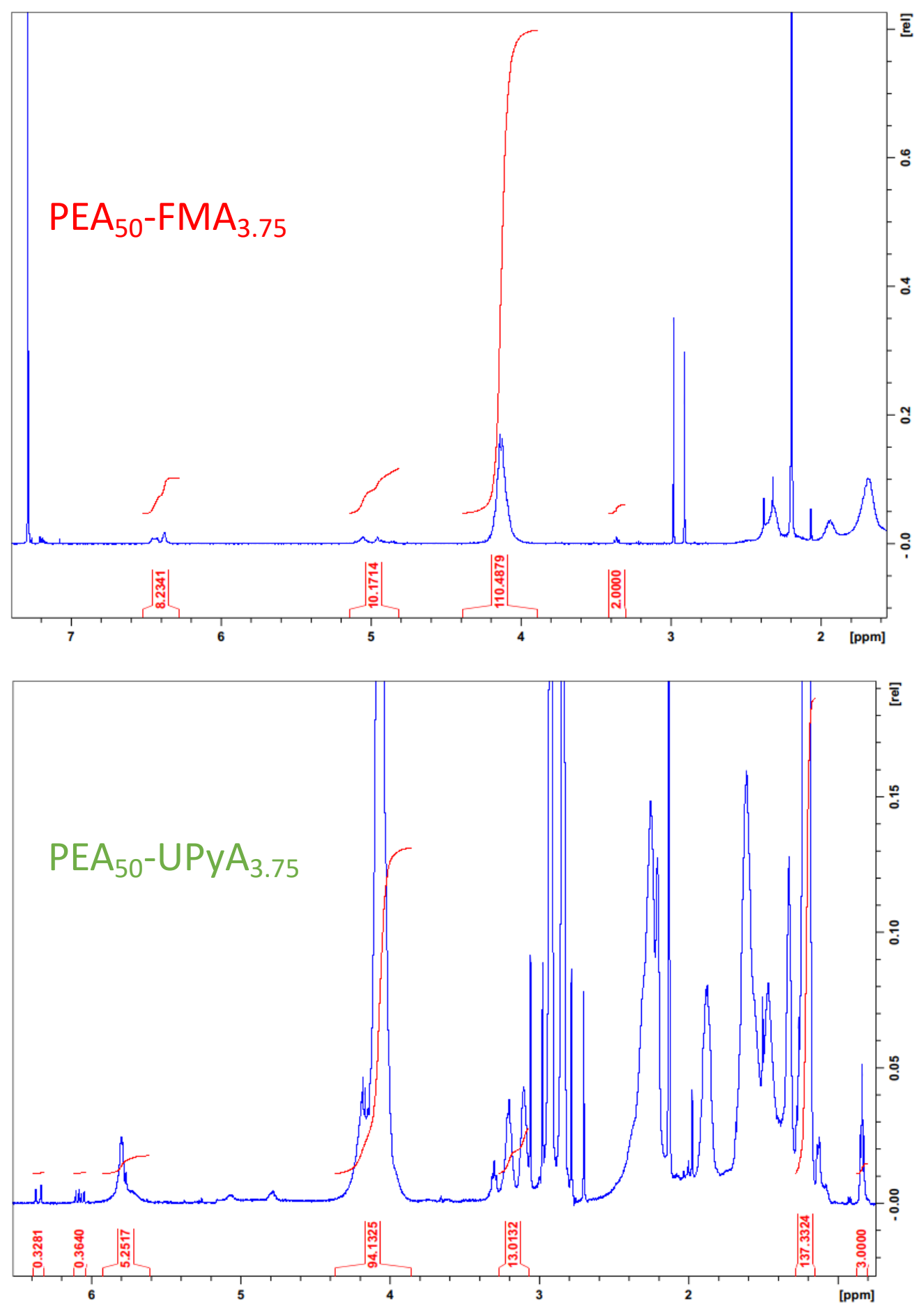

Figure S2. NMR data for PEA50-FMA3.75, PEA50-UPyA 3.75. 

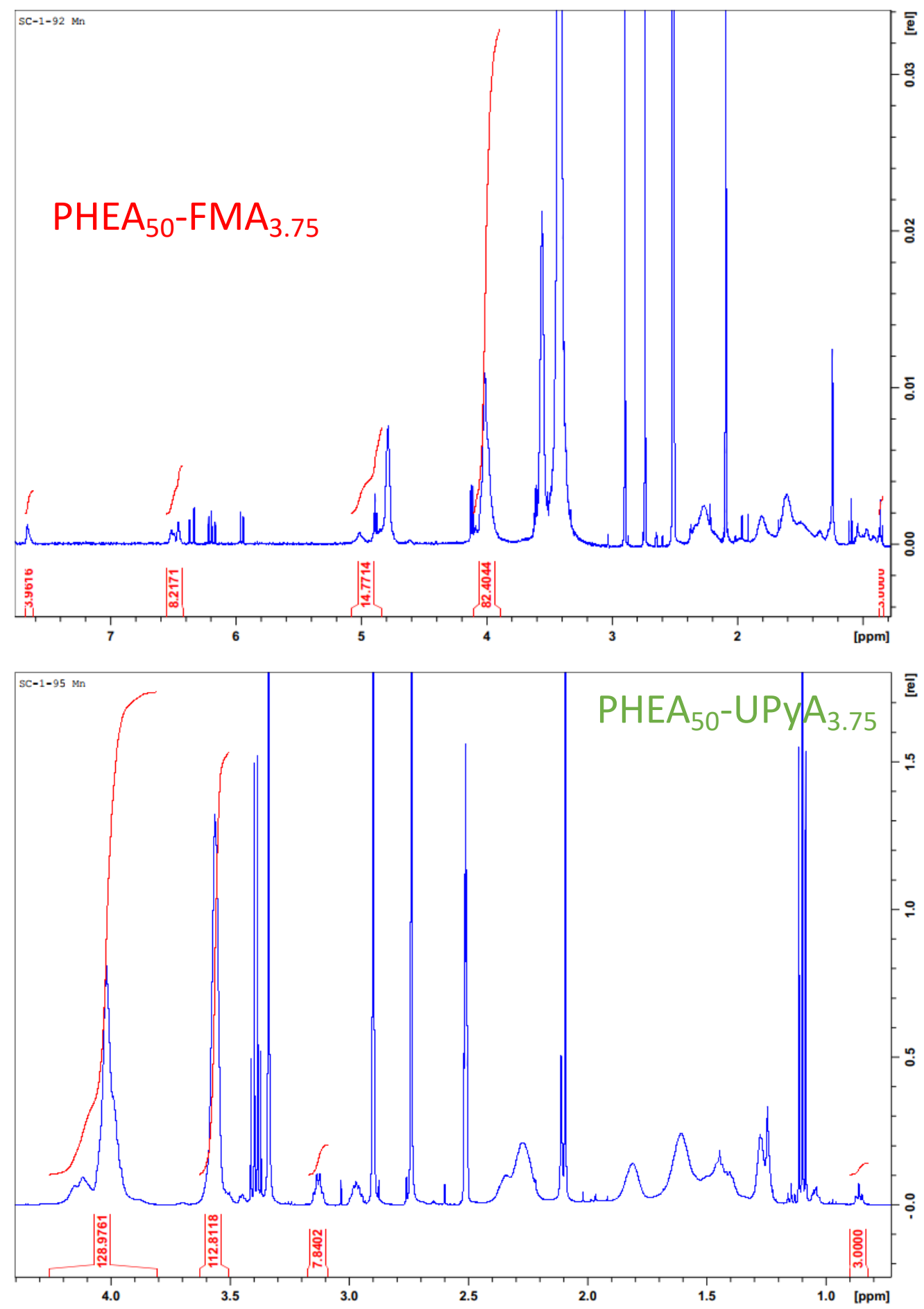

Figure S3. NMR data for PHEA50-FMA3.75, PHEA50-UPyA3.75. 


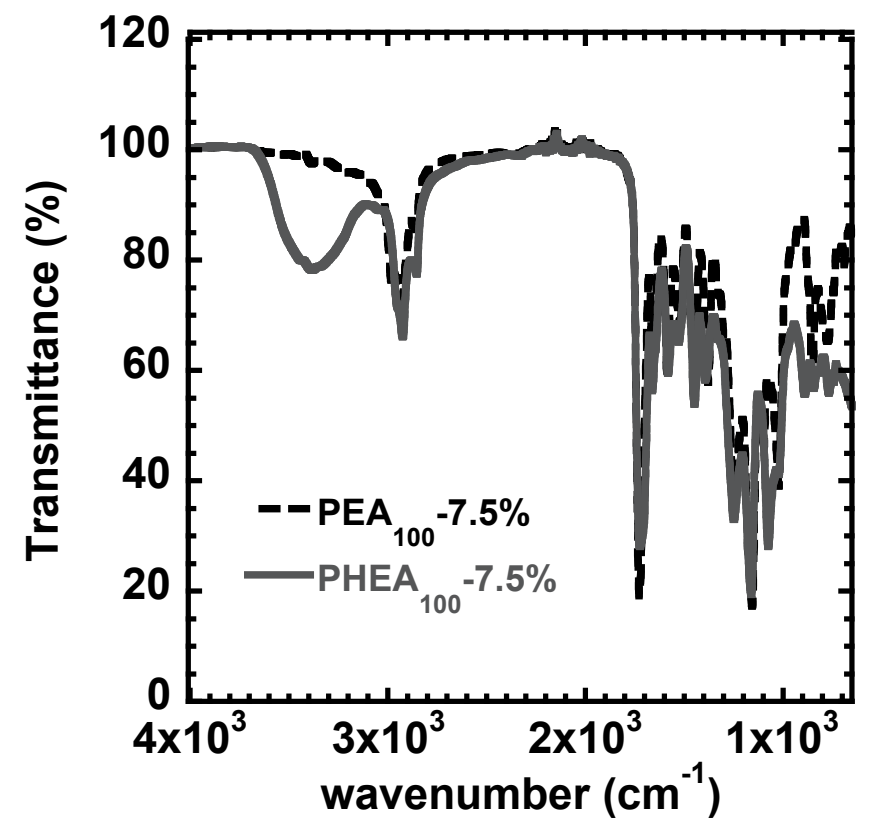

Figure S4. Infrared spectra of PEA $100-7.5 \%$. \& PHEA 100-7.5\% materials. 

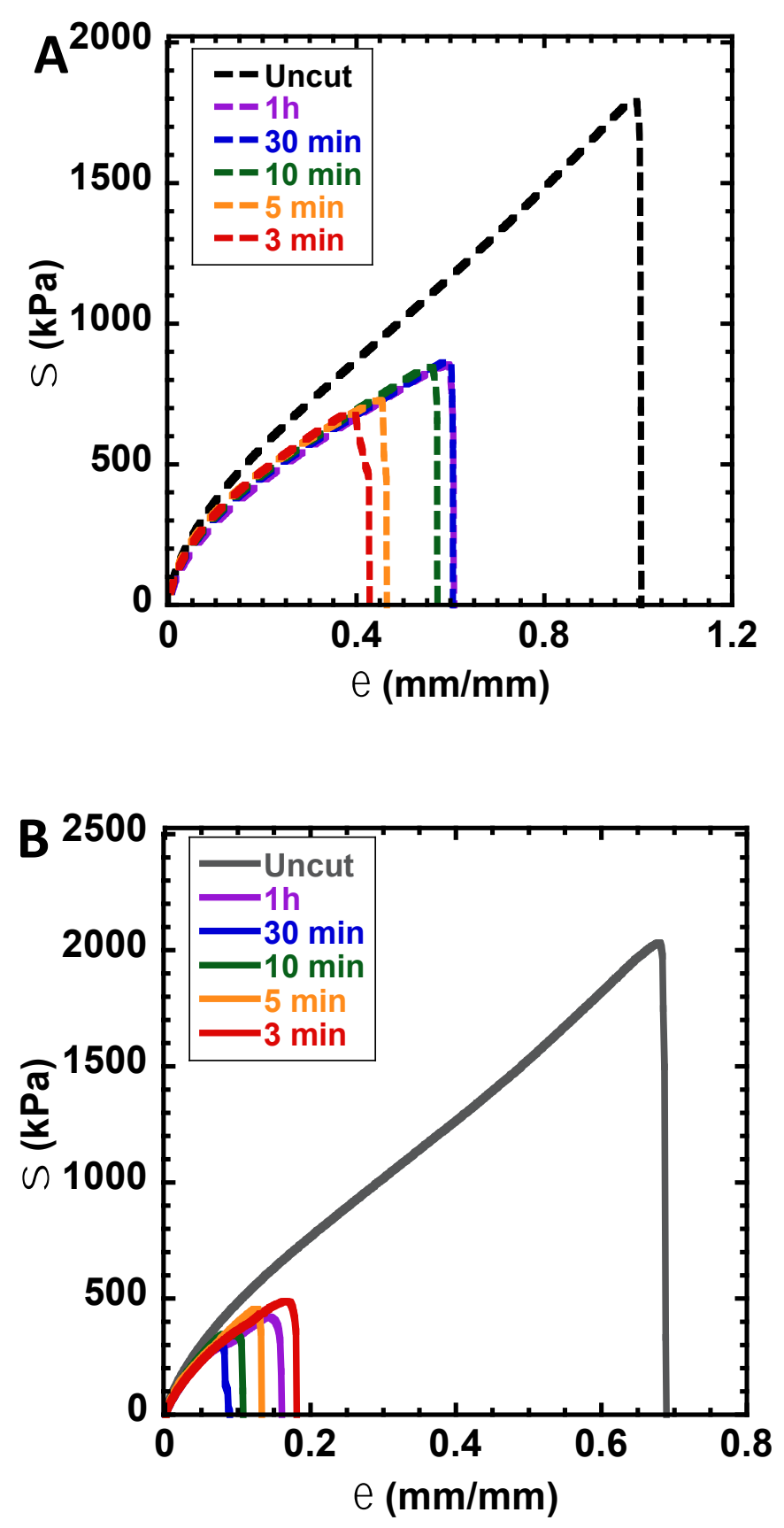

Figure S5. A) Self-healing at ambient temperature of PEA100-7.5\%. B) Self-healing at ambient temperature of PHEA $100-7.5 \%$. 

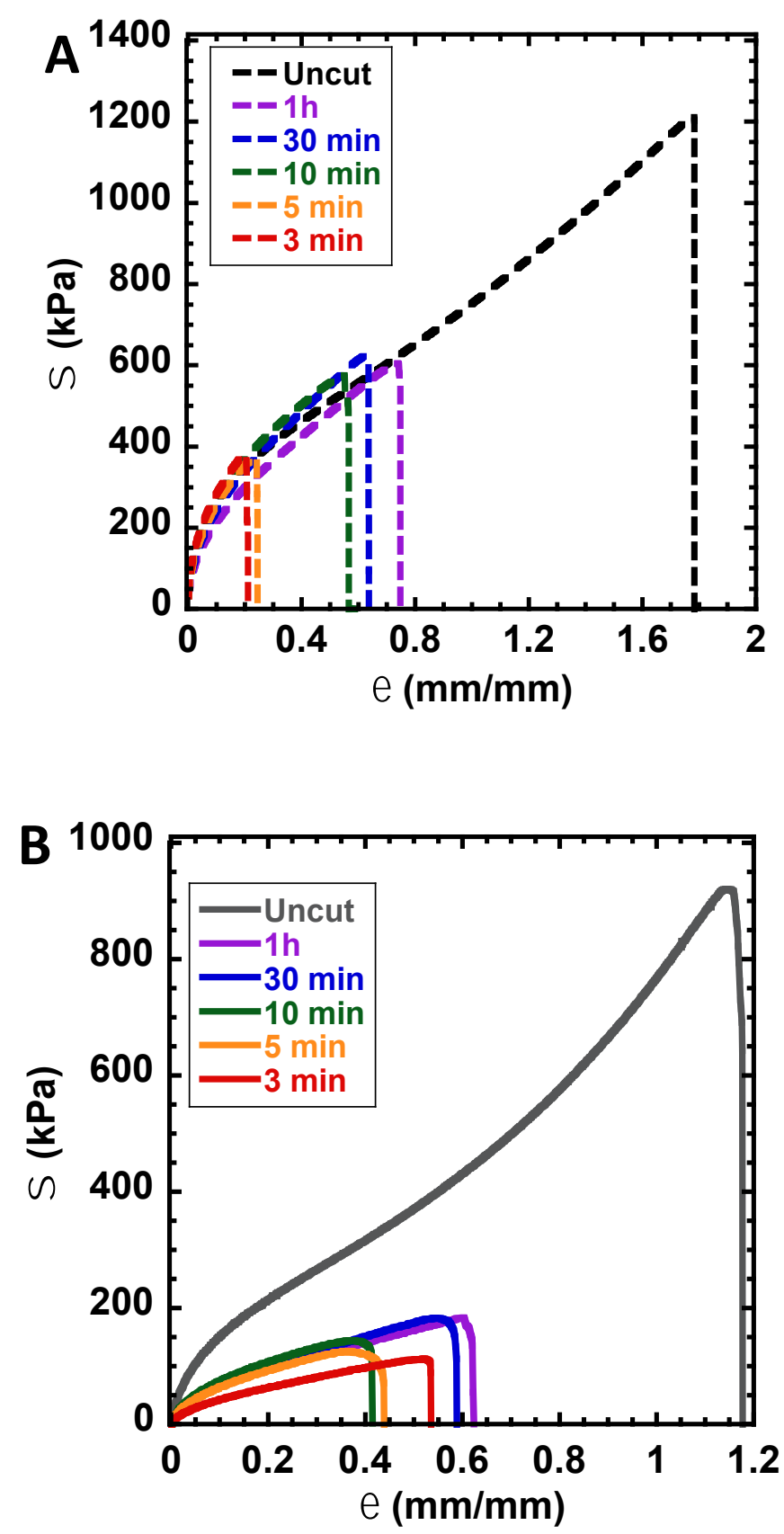

Figure S6. A) Self-healing at ambient temperature of PEA50-7.5\%. B) Self-healing at ambient temperature of PHEA $50-7.5 \%$. 


\section{References}

(1) Craig, A. F.; Clark, E. E.; Sahu, I. D.; Zhang, R.; Frantz, N. D.; Al-Abdul-Wahid, M. S.; Dabney-Smith, C.; Konkolewicz, D.; Lorigan, G. A. Tuning the size of styrene-maleic acid copolymer-lipid nanoparticles (SMALPs) using RAFT polymerization for biophysical studies. Biochim. Biophys. Acta - Biomembranes 2016, 1858, 2931-2939.

(2) Zhang, B.; Digby, Z. A.; Flum, J. A.; Foster, E. M.; Sparks, J. L.; Konkolewicz, D. Self-healing, malleable and creep limiting materials using both supramolecular and reversible covalent linkages. Polym. Chem. 2015, 6, 7368-7372.

(3) Zhang, B.; Ke, J.; Vakil, J. R.; Cummings, S. C.; Digby, Z. A.; Sparks, J. L.; Ye, Z.; Zanjani, M. B.; Konkolewicz, D. Dual-dynamic interpenetrated networks tuned through macromolecular architecture. Polym. Chem. 2019, 10, 6290-6304.

(4) Shergold, O. A.; Fleck, N. A.; Radford, D. The uniaxial stress versus strain response of pig skin and silicone rubber at low and high strain rates. Int J Impact Eng 2006, 32, 1384-1402. 